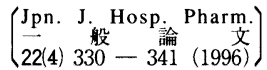

\title{
Studies on the Latex Agglutination Inhibition Method for Assay of Plasma Theophylline Concentration
}

\author{
JUNKO KIZU ${ }^{*} \dagger^{1}$, SHIGEKAZU WATANABE $\dagger^{1}$, HIDEKI ONO $\dagger^{1}$, JUN INATOMI $\dagger^{2}$, \\ KYOKO SASAKI $\dagger^{2}$, KAORU WATANABE $\dagger^{2}$, TAKASHI IGARASHI $\dagger^{2}$, \\ TSUTOMU IWATA $\dagger^{2}$, HIROSHI HAYAKAWA $\dagger^{2}$ and KAZUHIRO IMAI $\dagger^{3}$ \\ Department of Pharmacy, Branch Hospital, Faculty of Medicine, University of Tokyo ${ }^{1}$ \\ Department of Pediatrics, Branch Hospital, Faculty of Medicine, University of Tokyo $\dagger^{2}$
}

Department of Analytical Pharmacochemistry, Faculty of Pharmaceutical Science, University of Tokyo $\dagger^{3}$

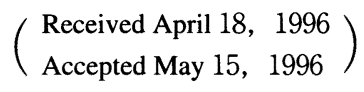

\begin{abstract}
We studied the latex agglutination inhibition method (the Biotrack system) for rapid measurement of plasma theophylline concentrations. Blood was collected from patients hospitalized for treatment of bronchial asthma and from healthy volunteers. The plasma theophylline concentrations of the samples were also measured by two other systems : fluorescence polarization immunoassay and high performance liquid chromatography (HPLC). When the results were compared, it was found that some combinations of Biotrack 516 units and cartridges afforded high plasma theophylline concentrations for some patients. Using HPLC, we found that the high values were not due to cross-reactivity with theophylline or caffeine metabolites. After careful investigation, the high values appeared to result from the characteristics of the individual Biotrack 5 16 units and cartridges used. Re-evaluation after improved materials were introduced into the system of Biotrack manufacturing yielded theophylline concentrations that correlated significantly with those obtained by HPLC.
\end{abstract}

Key words - bronchial asthma, plasma theophylline concentration, latex agglutination inhibition method, fluorescence polarization immunoassay, high performance liquid chromatography, whole blood

\section{Introduction}

Theophylline is widely employed in the treatment of bronchial asthma. The range of effective plasma theophylline concentrations is comparatively narrow, ranging from 10 to $20 \mu \mathrm{g} / \mathrm{ml}$, and various side effects are known to emerge when the plasma concentration exceeds $20 \mu \mathrm{g} / \mathrm{ml}$. Therefore, effective and safe theophylline therapy requires determination of the plasma concentration of the drug in each patient to establish the optimal $\operatorname{dose}^{1)}$.

$\dagger^{1,2}$ 東京都文京区目白台 3-28-6；3-28-6, Mejirodai, Bunkyo-ku, Tokyo, 112, Japan

$\ddagger^{3}$ 東京都文京区本郷 7-3-1; 7-3-1, Hongo, Bunkyo-ku, Tokyo, 113, Japan 
The established methods for assaying plasma theophylline concentrations include high performance liquid chromatography (HPLC) , fluorescence polarization immunoassay (FPIA) and enzyme immunoassay. However, all these assays are performed using plasma or serum samples and, therefore, are time-consuming as they require the preparation of plasma or serum samples.

The latex agglutination inhibition method, which utilizes an antibody against theophylline, is convenient since it only requires whole blood samples. The complete procedure is embodied in the Biotrack system, which is a rapid theophylline measurement system. This apparatus permits the measurement of the plasma theophylline concentration within approximately 3 min using 1 or 2 drops of whole blood.

In the present study, we investigated the accuracy, reproducibility and precision of the Biotrack system and compared it to FPIA and HPLC.

\section{Materials and Methods}

\section{Subjects}

1) Biotrack theophylline controls

Low level control（Eisai Co. Ltd., Tokyo, Japan) and high level control (Eisai) were used as whole blood controls for the Biotrack system quality control test.

2 ) Blood from patients

Group 1 was comprised of 90 blood samples from 29 bronchial asthma in-patients (17 males and 12 females aged 1-22 years) at the Department of Pediatrics, Branch Hospital, Faculty of Medicine, University of Tokyo, who were under treatment with oral sustained-release preparations of theophylline (Theolong, Eisai ; Theodur, Nikken Kagaku Co. Ltd., Tokyo, Japan） or intravenous drip infusions of aminophylline（Neophylline, Eisai） during the period from September to December 1993.

Grop 2 was comprised of 40 blood samples from 13 in-patients ( 9 males and 4 females aged $0-15$ years) treated under the same conditions as the group 1 patients in the same department during the period from May to November 1994.

3 ) Blood from healthy volunteers

Aminophylline was intravenously administered to 2 healthy consenting volunteers ( 1 male aged 40 years and 1 female aged 41 years) and 20 blood samples were collected from the subjects at various time intervals. In addition, aminophylline was again intravenously administered to the same subjects and 3 blood samples were obtained for calibration of the apparatus.

Blood samples obtained from patients and healthy volunteers were collected into tubes containing $2 \mathrm{mg}$ potassium EDTA as an anticoagulant, and were immediately used for measurement with the Biotrack system, after which the remaining samples were centrifuged and the plasma so obtained was preserved frozen until used in FPIA or HPLC assays.

\section{Measurements}

\section{1) Biotrack procedure}

Disposable "Biotrack Theophylline" cartridges (Eisai) consisted of theophylline-bound latex, antitheophylline antibody and 2 kinds of diluents. A measuring apparatus "Biotrack 516" (Ciba-Corning Diagnostics Co. Ltd., MA, USA) was used. 
After the bar code of the calibration card attached to the cartridge was read into the Biotrack 516 apparatus, the cartridge itself was inserted into the main unit. Measurement was commenced automatically by dripping 1 or 2 drops of whole blood (at least about $45 \mu \mathrm{l}$ ) into the sample groove of the cartridge.

Into the hemoglobin measurement unit was apportioned $6.4 \mu \mathrm{l}$ of the blood sample, where it was mixed with diluent 1 , which consisted of a hemolytic agent and an oxidant, to measure the hemoglobin concentration. Next, $9 \mu \mathrm{l}$ of the mixed sample was transferred to the immunoassay unit, and was mixed with diluent 2 , which consisted of a buffer, theophylline-bound latex particles and anti-theophylline antibody, resulting in a latex agglutination inhibition reaction. The absorbance at a wavelength of $565 \mathrm{~nm}$ was determined to calculate the content of theophylline in the mixed sample. The value so obtained was converted to the plasma concentration of theophylline on the basis of the calibration curve established for each lot of test cartridges and the hemoglobin measurement. The value calculated was indicated on the display of the Biotrack system ${ }^{2}$.

2 ) FPIA procedure

We used a "TDx-Theophylline II" reagent kit (Abbott, Co. Ltd., TX, USA), which consisted of a buffer solution for theophylline, a fluorescein-labeled theophylline tracer and an antibody to theophylline. A totally automatic fluorescence polarization apparatus "TDx" (Abbott) was used for measuring the plasma theophylline concentration using approximately $50 \mu$ l plasma samples.

\section{3 ) HPLC procedure}

The HPLC method for the simultaneous measurement of the plasma concentrations of theophylline and its metabolites described by Kodera et al. ${ }^{3)}$ and Hamasaki et al. ${ }^{4)}$ was modified to allow simultaneous determination of the plasma concentrations of not only theophylline and its metabolites, but also of caffeine and its metabolites.

The test compounds to be separated were theophylline, 1-methyluric acid, 3-methylxanthine, 1methylxanthine, 1,3-dimethyluric acid, theobromine, 1,7-dimethyluric acid, paraxanthine, 1,3,7trimethyluric acid and caffeine.

The HPLC apparatus consisted of the following components : an LC- 5 A pump (Shimadzu), an L-4200 ultraviolet absorption detector (Hitachi), a Chromatopac C-R 2 AX recorder (Shimadzu), a KHP-U 1-130A sample injector (Kyowa Precision), a TSK ODS- $80_{\mathrm{TM}}$ reverse-phase column $(250 \times 4.6 \mathrm{~mm}$ i.d., $5 \mu \mathrm{m}$, Tosoh) and a New Guard TM Column precolumn $(15 \times 3.2 \mathrm{~mm}$ i.d., $7 \mu \mathrm{m}$, Tosoh $)$.

The HPLC column was operated at room temperature with the flow rate of the mobile phase set to $1.0 \mathrm{ml} /$ $\min$. The detection wavelength was $275 \mathrm{~nm}$. The mobile phase was a mixture of $20 \mathrm{mM}$ sodium acetate buffer

(pH4.8), acetonitrile, and methanol in the proportions 900:35:65 v/v/v.

To $100 \mu \mathrm{l}$ of plasma was added $300 \mu \mathrm{l}$ of an acetonitrile solution containing $0.3 \mu \mathrm{g}$ of $\beta-$ hydroxyethyltheophylline as an internal standard. After thorough stirring, the sample was deproteinized by centrifuging at $5,000 \times \mathrm{g}$ for $5 \mathrm{~min}$, and $300 \mu \mathrm{l}$ of the supernatant was evaporated to dryness at $40^{\circ} \mathrm{C}$. The residue was dissolved in $30 \mu \mathrm{l}$ of the mobile phase and $5 \mu \mathrm{l}$ of the solution was injected onto the HPLC column for separation. The plasma concentrations of the test substances were calculated from their peak height ratios relative to the internal standard, using the calibration curve.

\section{Assessment of reproducibility of the Biotrack system}

Eight successive measurements were made with 2 Biotrack theophylline controls (low level and high level) 
and blood samples from 2 patients (low level and hight level) to assess the within-run reproducibility of the Biotrack system.

Three measurements each were made for additional blood samples from 2 patients (low level and high level) on 4 consecutive days to assess the day-to-day precision of the Biotrack system (Biotrack 516, serial No. DJO 1858 and lot No. TH20340 cartridges were used).

\section{Comparison of plasma theophylline concentrations between the Biotrack system and FPIA or HPLC}

Plasma theophylline concentrations of 110 blood samples obtained from group 1 patients and healthy volunteers were measured using the Biotrack system, FPIA, and HPLC. The regression equations and the correlation coefficients of measurements compared between the Biotrack system and FPIA or HPLC were calculated, and the data was also analyzed by paired t-tests.

In cases where 3 blood samples or more obtained from 1 subject the Biotrack, HPLC and FPIA measurements were analyzed for that individual by paired $t$-tests.

Using 20 blood samples obtained from 2 healthy volunteers, the elimination half-life of theophylline was calculated from the plasma concentrations obtained by the 3 assay methods. (Biotrack 516, serial No. DJO1858 and lot No. TH20340 cartridges were used).

\section{Consideration of factors contributing to the high values observed in the Biotrack system}

1 ) Correlation between theophylline or caffeine metabolites and high values obtained using the Biotrack system

To determine the effects of theophylline and caffeine metabolites on the measurement of plasma theophylline concentrations, measurements were made with 110 blood samples by the Biotrack and HPLC methods, and the relationship between the differences in the plasma theophylline concentrations determined by the 2 methods and the concentrations of theophylline and caffeine metabolites measured by HPLC was examined.

2 ) Differences between individual Biotrack 516 units and individual cartridges

Two blood samples of differing theophylline concentrations were obtained from a healthy volunteer after intravenous administration of aminophylline, and 8 successive measurements of the plasma theophylline concentrations were made for each sample, using 3 Biotrack 516 units (serial Nos. DJO1858, DNO1086U, and DQO2018U) and cartridges from lot Nos. TH20325, TH20341, TH30113, and TH30117. The values obtained in these measurements were analyzed by a two-way analysis of variance with repetitions.

Blood samples obtained from another healthy volunteer were similarly assayed and the measured values were analyzed by the same statistical test.

6. Comparison of plasma theophylline concentrations between the improved Biotrack system and HPLC

Plasma theophylline concentrations were measured for 40 blood samples obtained from group 2 patients, using a Biotrack 516 apparatus (serial No. DQO2018U) and cartridges from lot No. TH30117. These blood samples were also analyzed by HPLC. The regression equation and the correlation coefficient for the 2 methods were determined and the data were also analyzed by a paired $t$-test. 


\section{Results and Discussion}

\section{Reproducibility of the Biotrack system}

The coefficient of variation for within-run reproducibility of Biotrack results ranged from $1.56 \%$ to $5.55 \%$

(Table 1 ), and the coefficient of variation for day-to-day precision ranged from $2.20 \%$ to $3.85 \%$ (Table 2 ), which are close to the results reported by Ishizawa et al. ${ }^{5)}$ and Shimizu et al. ${ }^{6)}$

Table 1. Within-run Reproducibility of Theophylline Concentrations in Biotrack Theophylline Controls and Blood Samples from Patients

\begin{tabular}{c|c|c}
\hline & $\begin{array}{c}\text { Theophylline concentration } \\
(\mu \mathrm{g} / \mathrm{ml})\end{array}$ & C.V.(\%) \\
& $\begin{array}{c}\text { Mean } \pm \text { S.D. }(\mathrm{n}=8) \\
\text { Biotrack theophylline controls }\end{array}$ & \\
Low level control & $12.50 \pm 0.69$ & 5.55 \\
High level control & $25.95 \pm 0.69$ & 2.64 \\
\hline Blood samples from patients & & \\
Low level blood sample & $10.60 \pm 0.17$ & 1.56 \\
High level blood sample & $18.79 \pm 0.77$ & 4.08 \\
\hline
\end{tabular}

Each control and blood sample was measured 8 times in succession.

Measurements performed using the Biotrack 516 with the serial No. DJO1858 and cartridges of lot No.TH20340.

Table 2. Day-to-day Precision of Theophylline Concentrations in Blood Samples from Patients

\begin{tabular}{rl|c|c}
\hline & & $\begin{array}{c}\text { Theophylline concentration } \\
(\mu \mathrm{g} / \mathrm{ml})\end{array}$ & C.V.(\%) \\
& No. 1 & $7.55 \pm 0.17$ & 2.20 \\
Low level blood sample & No. 2 & $7.68 \pm 0.23$ & 2.97 \\
& No. 3 & $7.50 \pm 0.19$ & 2.49 \\
\hline Nigh level blood sample & No. 2 & $20.70 \pm 0.55$ & 2.67 \\
& No. 3 & $21.20 \pm 0.48$ & 2.29 \\
& $20.48 \pm 0.79$ & 3.85 \\
\hline
\end{tabular}

Each blood sample was divided into 3 aliquots (Nos. 1-3), and the theophylline concentration of each aliquot was measured on 4 consecutive days.

Measurements performed using the Biotrack 516 with the serial No. DJO1858 and cartridges of lot No. TH20340.

The coefficient of variation for within-run reproducibility for the HPLC method was $1.1 \%$ and that for dayto-day precision was $1.5 \% \quad(\mathrm{n}=8)$.

According to Nakamura et al. ${ }^{7)}$, the coefficient of variation for within-run reproducibility of FPIA results was $1.7 \%$ or less and that for day-to-day precision was $2.2 \%$ or less. Hishida et al. ${ }^{8)}$, on the other hand, 
reported that the coefficient of variation for FPIA within-run reproducibility was $1.9 \%$ or less and that for day -to-day precision was $3.5 \%$ or less.

The present study shows that the coefficients of variation for the Biotrack system were greater than those for the HPLC and FPIA systems, but we regard them to be fully satisfactory.

\section{Comparison of plasma theophylline concentrations between the Biotrack system and FPIA or HPLC}

1 ) Comparative analysis of plasma theophylline concentrations measured by the 3 methods

Figure 1 shows the correlation between plasma theophylline concentrations measured by the Biotrack system and FPIA. Samples with theophylline concentrations of $2.5 \mu \mathrm{g} / \mathrm{ml}$ or less ( 2 in 110 blood samples) as measured by the Biotrack system were exempted since no effective measurement could be made with these samples. The regression equation was $y=1.060 x+0.078$ ( $y:$ Biotrack, $x:$ FPIA), and the correlation coefficient $(r)$ was $0.973(p<0.001)$. However, the paired $t$-test revealed a significant difference between the 2 sets of measurements obtained by these methods $(p<0.01)$. The mean of value obtained by the Biotrack system was $12.22 \mu \mathrm{g} / \mathrm{ml}$ whereas the mean value obtained by FPIA was $11.45 \mu \mathrm{g} / \mathrm{ml}$, the former value being $6.72 \%$ higher. Likewise, Shimizu et al. ${ }^{6}$ have reported that Biotrack values tend to be somewhat higher than FPIA values.

Figure 2 shows the correlation between plasma theophylline concentrations measured by the Biotrack system

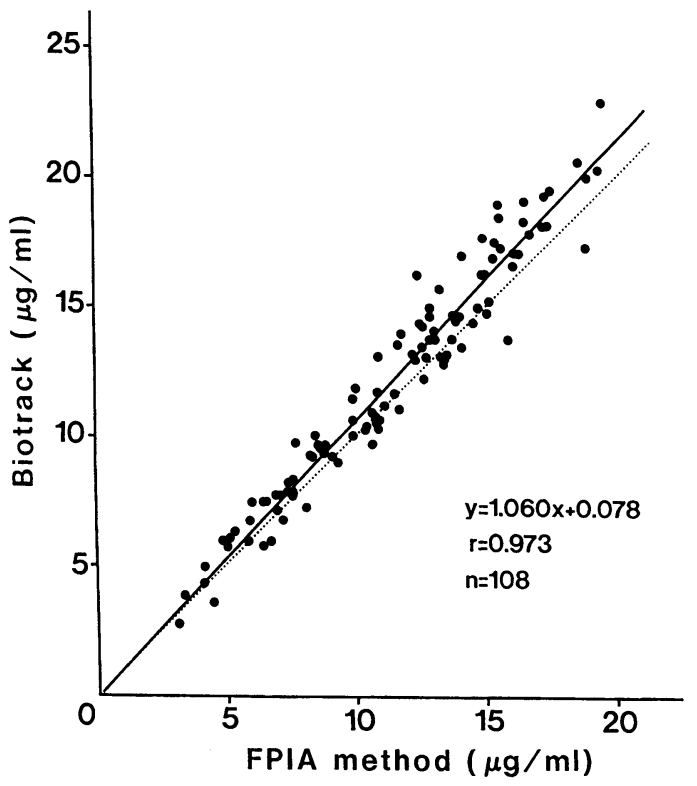

Fig. 1. Correlation between Plasma Theophylline Concentrations of Patients in Group 1 and Healthy Volunteers Obtained using the Biotrack System and by FPIA

- regression line $\quad \cdots \cdots: \mathrm{y}=\mathbf{x}$

(Measurements performed using the Biotrack 516 with the serial No.DJO1858 and cartridges of lot No.TH20340)

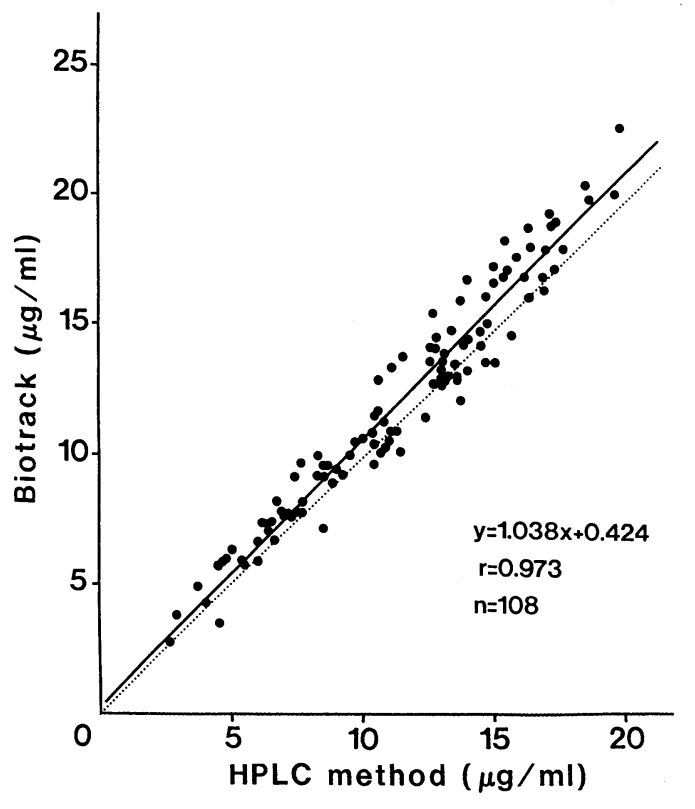

Fig. 2. Correlation between Plasma Theophylline Concentrations of Patients in Group 1 and Healthy Volunteers Obtained Using the Biotrack System and by HPLC

— : regression line $\quad \cdots \cdots: \mathrm{y}=\mathrm{x}$

(Measurements performed using the Biotrack 516 with the serial No.DJO1858 and cartridges of lot No.TH20340) 
and HPLC. The regression equation was $y=1.038 \mathrm{x}+0.424$ ( $\mathrm{y}:$ Biotrack, $\mathrm{x}:$ HPLC), and the correlation coefficient $(\mathrm{r})$ was $0.973(\mathrm{p}<0.001)$. The paired $\mathrm{t}$-test revealed a significant difference between the 2 sets of measurements obtained by these methods $(p<0.01)$. The mean value obtained by HPLC was $11.36 \mu \mathrm{g} /$ $\mathrm{ml}$. The mean of the Biotrack values was $7.57 \%$ higher than that of the HPLC values.

There was an excellent correlation between the plasma theophylline concentrations measured by FPIA and HPLC ; the regression equation was $y=0.972 x+0.411$ ( $y$ : FPIA, $x:$ HPLC) and the correlation coefficient (r) was $0.992(p<0.001)$. The paired $t$-test revealed no significant difference between the 2 sets of measurements obtained by these methods $(p>0.05)$, and the mean of the FPIA values was only $0.79 \%$ higher than that of the HPLC values.

Thus, the results above indicate that plasma theophylline concentrations measured by the Biotrack system were significantly higher than those measured by FPIA or HPLC.

2 ) Comparative analysis of individual subjects

For 13 patients and 2 healthy volunteers from whom at least 3 samples were available, paired t-tests were used to compare measurements obtained by Biotrack and FPIA, Biotrack and HPLC, and FPIA and HPLC

(Table 3). The results revealed that Biotrack values were not always significantly higher than the corresponding FPIA and HPLC values ; only the Biotrack values for certain individuals were consistently higher than the HPLC or FPIA values.

Table 3. Differences between Theophylline Assays Using the Biotrack System, HPLC and FPIA in Individual Subjects

\begin{tabular}{|c|c|c|c|c|c|c|}
\hline Subject & Sex & $\begin{array}{c}\text { Age } \\
\text { (years) }\end{array}$ & $\mathrm{n}$ & $\begin{array}{c}\text { Biotrack } \\
\text { vs } \\
\text { FPIA }\end{array}$ & $\begin{array}{c}\text { Biotrack } \\
\text { vs } \\
\text { HPLC }\end{array}$ & $\begin{array}{c}\text { FPIA } \\
\text { vs } \\
\text { HPLC }\end{array}$ \\
\hline Healthy volunteer & F & 41 & 12 & $* *$ & $* *$ & n.s. \\
\hline Healthy volunteer & M & 40 & 6 & n.s. & n.s. & n.s. \\
\hline Patient & F & 9 & 7 & $* *$ & $* *$ & n.s. \\
\hline Patient & $\mathbf{M}$ & 7 & 7 & $* *$ & $* *$ & n.s. \\
\hline Patient & M & 1 & 5 & $* *$ & $* *$ & n.s. \\
\hline Patient & M & 15 & 5 & $*$ & $* *$ & n.s. \\
\hline Patient & F & 4 & 3 & $*$ & $*$ & n.s. \\
\hline Patient & $\mathbf{M}$ & 4 & 6 & n.s. & $* *$ & $*$ \\
\hline Patient & $\mathbf{F}$ & 2 & 6 & n.s. & $* *$ & $*$ \\
\hline Patient & $\mathbf{M}$ & 4 & 3 & n.s. & $*$ & n.s. \\
\hline Patient & $\mathbf{M}$ & 4 & 3 & n.s. & n.s. & $*$ \\
\hline Patient & $\mathbf{F}$ & 16 & 12 & n.s. & n.s. & n.s. \\
\hline Patient & $\mathbf{M}$ & 9 & 3 & n.s. & n.s. & n.s. \\
\hline Patient & $\mathbf{M}$ & 6 & 3 & n.s. & n.s. & n.s. \\
\hline Patient & $\mathbf{M}$ & 2 & 4 & n.s. & n.s. & n.s. \\
\hline
\end{tabular}

$* * \mathrm{P}<0.01, * \mathrm{P}<0.05$, n.s. not significant

Paired t-tests were used to compare measurements obtained by Biotrack and FPIA, Biotrack and HPLC, and FPIA and HPLC for each subject for whom at least 3 blood samples were available.

Biotrack measurements performed using the Biotrack 516 with the serial No. DJO1858 and cartridges of lot No. TH20340. 
Subjects with significantly high Biotrack theophylline measurements showed no other significant differences, with respect to clinical characteristics such as sex, age, severity of disease, method of therapy, course of treatment, etc. compared to the other subjects. Moreover, the cause of the differences in the measured values was also investigated in relation to variables such as the route of administration of the theophylline preparation as well as routine hematological and biochemical data, but the results indicated no significant correlations with any of these factors ${ }^{9)}$.

3 ) Comparison of half-lives determined by the 3 methods

Figures 3 and 4 show the changes with time in plasma theophylline concentrations as determined by the Biotrack system, FPIA, and HPLC from 20 blood samples obtained after intravenous injection of aminophylline into 2 healthy volunteers.

In the case shown in Figure $3($ female aged 41 years, nonsmoker), paired t-tests revealed a significant difference between Biotrack values and HPLC values, as well as between Biotrack values and FPIA values ( $p$ $<0.01)$. However, no significant difference was observed between FPIA values and HPLC values $(p>0.05)$.

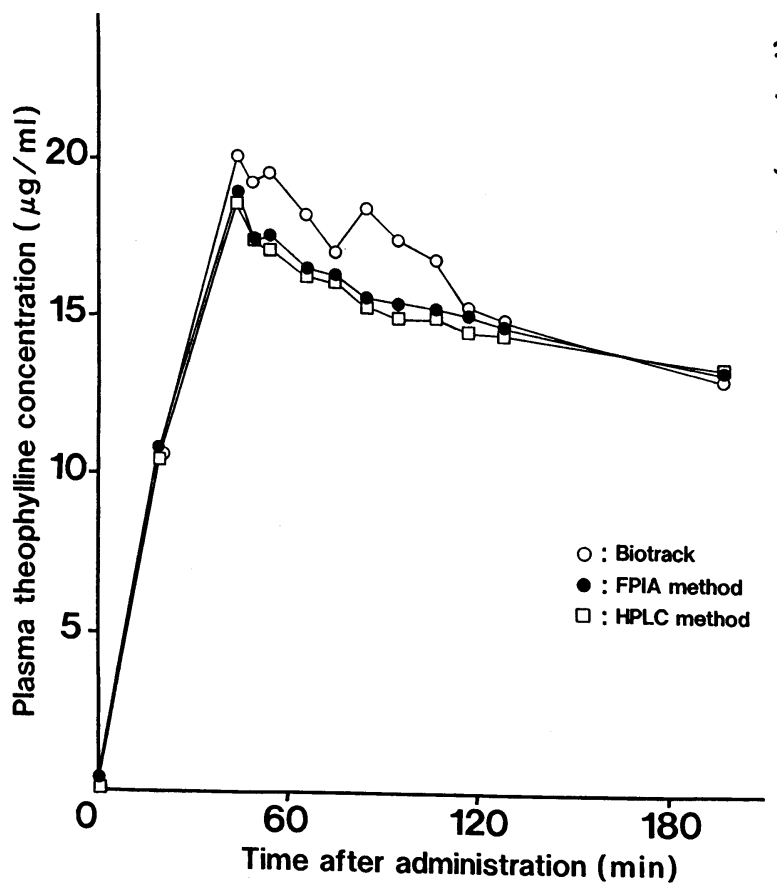

Fig. 3. Changes with Time of Plasma Theophylline Concentrations as Determined by the Biotrack System, FPIA and HPLC from Samples Collected after Intravenous Injection of Aminophylline into a Healthy Volunteer (

(Measurements performed using the Biotrack 516 with the serial No.DJO1858 and cartridges of lot No.TH20340)

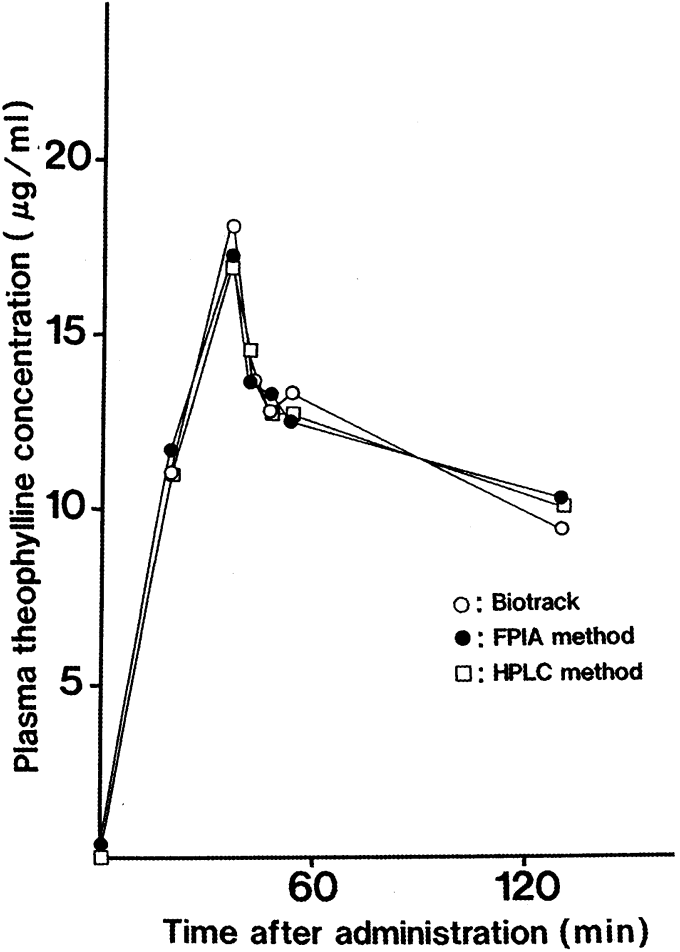

Fig. 4. Changes with Time of Plasma Theophylline Concentrations as Determined by the Biotrack System, FPLA and HPLC from Samples Collected after Intravenous Injection of Aminophylline into a Healthy Volunteer ( $\square$; smoker).

(Measurements performed using the Biotrack 516 with the serial No.DJO1858 and cartridges of lot No.TH20340) 
In addition, the half-life, as determined by the nonlinear least square method, differed considerably according to the method used, and was $4.17 \mathrm{~h}$ on the basis of Biotrack values as compared with $6.47 \mathrm{~h}$ from the FPIA data and $6.65 \mathrm{~h}$ from the HPLC data. Incidentally, the half-life of theophylline administered to healthy nonsmokers was reported to be $8.1 \pm 2.4 \mathrm{~h}$ by Horai et al. ${ }^{10)}$ and $7.6 \pm 1.3 \mathrm{~h}$ by Cusac et al. ${ }^{11)}$. Clearance in the present case appeared to be normal according to measurements performed by HPLC and FPIA, but was unusually rapid according to the Biotrack measurements.

By contrast, in the case shown by Figure 4 , male aged 40 years, smoker), although the measurements were made under the same conditions as in the case shown by Figure 3 , paired t-tests revealed no significant differences among the measured values obtained by the Biotrack system, by HPLC, and by FPIA. The half-life was $3.07 \mathrm{~h}$ according to the Biotrack system, $3.57 \mathrm{~h}$ according to HPLC, and $4.29 \mathrm{~h}$ according to FPIA. The half-life of theophylline in healthy smokers was reported to be $4.1 \pm 1.2 \mathrm{~h}$ by Jenne et al. ${ }^{12)}$ and $4.31 \pm 1.35 \mathrm{~h}$ by Hunt et al. ${ }^{13)}$. Their reports indicate that the half-life of this compound in healthy smokers is shorter than in healthy nonsmokers. In the present study, all the methods of measurement confirmed that the half-life of theophylline was shorter in healthy smokers than in healthy nonsmokers, consistent with the literature data.

Therefore, determination of the half-life of theophylline on the basis of Biotrack measurements has indicated that for patients in whom Biotrack yielded significantly higher theophylline concentrations, a large difference with respect to the half-life, would also result from the Biotrack system, and this point requires attention in clinical applications.

\section{Consideration of factors contributing to the high values observed in the Biotrack system}

1 ) Correlation between theophylline or caffeine metabolites and high values obtained by the Biotrack system

The factors responsible for the significantly higher concentrations obtained by the Biotrack system for some patients might include, for example, cross-reactivity with similar compounds such as metabolites of theophylline or caffeine in the blood.

In order to ascertain the existence of such cross-reactivity or otherwise, the relationship between the concentrations of each metabolite and the difference in theophylline levels obtained using the Biotrack system and by HPLC was investigated for 108 samples. However, all the correlation coefficients were less than 0.15 , thus, no correlation was detected $(1$-methyluric acid, $r=0.009 ; 1$-methylxanthine, $r=0.014 ; 3$ methylxanthine, $\mathrm{r}=0.026 ; 1,3$-dimethyluric acid, $\mathrm{r}=0.141$; theobromine, $\mathrm{r}=0.001$; paraxanthine, $\mathrm{r}=$ 0.013 ; caffeine, $r=0.077 ; 1,7$-dimethyluric acid and $1,3,7$-trimethyluric acid were not detected in any of the samples).

This suggests that the high values obtained by the Biotrack system are not due to cross-reactivity with these metabolites.

2 ) Differences between individual Biotrack 516 units and individual cartridges

The theophylline concentrations of 2 blood samples (samples 1 and 2) of differing theophylline concentrations, obtained from a healthy volunteer $(\square)$ with a tendency toward high values, were measured using 3 Biotrack 516 uints and cartridges from 4 different lots. The data so obtained are shown in Table 4 . The values were analyzed by a two-way layout analysis of variance with repetitions, which revealed significant differences among individual Biotrack 516 units and cartridges as well as among equipment and cartridge combinations for both low concentration and high concentration samples $(\mathrm{p}<0.01)$. The theophylline 
Table 4. Theophylline Concentrations Obtained Using 3 Different Biotrack 516 Units and 4 Different Cartridges

\begin{tabular}{|c|c|c|c|c|c|}
\hline \multicolumn{6}{|c|}{ Theophylline concentration $(\mu \mathrm{g} / \mathrm{ml})$} \\
\hline & \multirow{2}{*}{$\begin{array}{l}\text { Cartridge } \\
\text { lot number }\end{array}$} & \multicolumn{3}{|c|}{ Biotrack 516 apparatus serial number } & \multirow[b]{2}{*}{ Mean \pm S.D. $(n=24)$} \\
\hline & & DJO1858 & $\begin{array}{c}\text { DNO1086U } \\
\text { Mean } \pm \text { S.D. }(n=8)\end{array}$ & DQO2018U & \\
\hline \multirow{5}{*}{$\begin{array}{c}\text { Sample 1 } \\
\text { (Low level blood sample) }\end{array}$} & TH20325 & $7.58 \pm 0.16$ & $7.14 \pm 0.33$ & $6.98 \pm 0.17$ & $7.23 \pm 0.34$ \\
\hline & TH20341 & $7.79 \pm 0.31$ & $7.39 \pm 0.20$ & $7.15 \pm 0.20$ & $7.44 \pm 0.36$ \\
\hline & TH30113 & $6.86 \pm 0.26$ & $6.84 \pm 0.22$ & $6.74 \pm 0.34$ & $6.81 \pm 0.28$ \\
\hline & TH30117 & $6.73 \pm 0.25$ & $6.94 \pm 0.25$ & $6.73 \pm 0.19$ & $6.80 \pm 0.25$ \\
\hline & MeantS.D. $(n=32)$ & $7.24 \pm 0.52$ & $7.08 \pm 0.33$ & $6.90 \pm 0.29$ & $7.07 \pm 0.42(n=96)$ \\
\hline \multirow{5}{*}{$\begin{array}{c}\text { Sample } 2 \\
\text { (High level blood sample) }\end{array}$} & TH20325 & $19.94 \pm 0.69$ & $18.95 \pm 0.60$ & $18.00 \pm 0.41$ & $18.96 \pm 0.98$ \\
\hline & TH20341 & $20.74 \pm 0.21$ & $19.31 \pm 0.58$ & $18.79 \pm 0.68$ & $19.61 \pm 0.98$ \\
\hline & TH30113 & $18.85 \pm 0.71$ & $18.89 \pm 1.00$ & $18.36 \pm 0.66$ & $18.70 \pm 0.84$ \\
\hline & TH30117 & $18.34 \pm 0.54$ & $18.58 \pm 0.67$ & $17.88 \pm 0.81$ & $18.26 \pm 0.74$ \\
\hline & MeantS.D. $(n=32)$ & $19.47 \pm 1.10$ & $18.93 \pm 0.78$ & $18.26 \pm 0.74$ & $18.88 \pm 1.02(n=96)$ \\
\hline
\end{tabular}

Three Biotrack 516 units and cartridges from 4 lots were used for measuring the theophylline concentrations of a healthy volunteer ( () for whom the Biotrack system tended to yield relatively high values.

concentrations of the same 2 samples were also measured by HPLC, and the results were $6.85 \pm 0.06 \mu \mathrm{g} / \mathrm{ml}$ and $18.60 \pm 0.25 \mu \mathrm{g} / \mathrm{ml} \quad(\mathrm{n}=3)$.

The same measurements were made for 1 blood sample (sample 3 ) from a healthy volunteer ( showed no tendency toward high values. Again, the values were analyzed by a two-way layout analysis of variance with repetitions, but no significant differences were recognized among Biotrack 516 units, among cartridges, or among equipment and cartridge combinations $(p>0.01)$.

The combination of Biotrack 516 apparatus DJO1858 and a cartridge from lot No.TH20340 (which was manufactured in the same period as cartridges in lot No.TH20341 and, therefore, was considered to be of the same lot), used for measurement of 108 samples from patients and healthy volunteers, yielded the highest values for both sample 1 and sample 2 . The values, when compared with those obtained by HPLC using a t-test, also revealed a significant difference for both samples $(\mathrm{p}<0.01)$. However, measurement of sample 3 showed no significant difference from values obtained by HPLC.

It is apparent that this apparatus (DJO1858) and cartridge (TH20341) combination did not a yield high value for each sample, but only for a subset of samples.

According to the manufacturer (Ciba-Corning Diagnostics), different materials were employed in the fabrication of the cuvettes in the measuring section of the cartridges of the TH 2 XXXX and TH 3 XXXX series. In particular, from series TH 3 XXXX onward, more uniform transparency was attained and the method of inspection was changed from visual to optical inspection. Moreover, concomitant with these cartridge alterations, the set point of the variable resistor in the light receiver was changed in Biotrack 516 units with serial numbers in the DNO and DNQ series (Ciba-Corning Diagnostics Co. Ltd., personal communication).

These facts suggest that the effects of characteristics of the blood from certain particular subjects were reflected in the high values obtained by the Biotrack system prior to improvement of its apparatus and cartridges, but the precise nature of the effects in question remains obscure. Futheremore, the cause of the different halflife measurements shown in Figure 3 is obscure, so there is room for further investigation. 


\section{Comparison of plasma theophylline concentrations between the improved Biotrack system and} HPLC

Figure 5 indicates the correlation between plasma theophylline concentrations of patients in group 2 , measured using the improved Biotrack system and by HPLC. An excellent correlation was obtained ; the regression equation was $y=0.971 x+0.490$ ( $y$ : Biotrack, $x:$ HPLC), and the correlation coefficient $(r)$ was $0.978(\mathrm{p}<0.001)$. A paired $\mathrm{t}$-test revealed no significant difference between the 2 sets of measurements $(\mathrm{p}$ $>0.05)$.

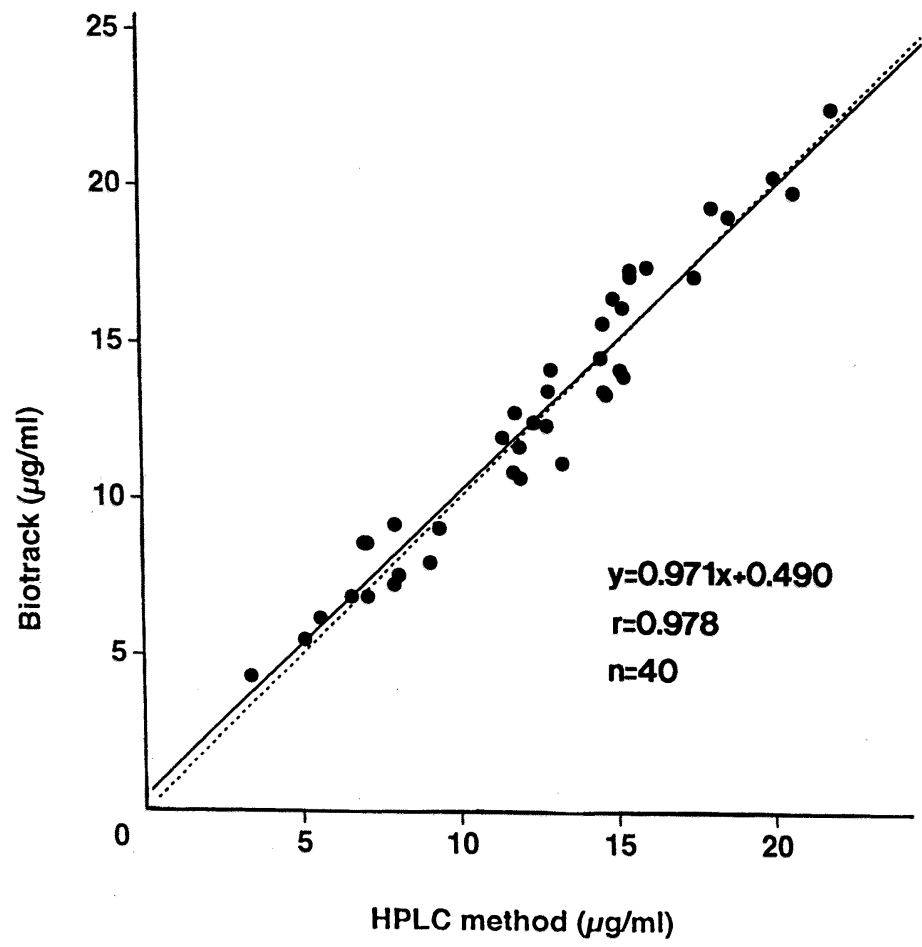

Fig. 5. Correlation between Plasma Theophylline Concentrations of Patients in Group 2 Obtained Using the Improved Biotrack System and by HPLC

- : regression line $\quad \cdots \cdots: y=x$

(Measurements performed using the Biotrack 516 with the serial No.DQO2018 U and cartridges of lot No.TH30117)

The mean of value obtained by the Biotrack system was only $1.10 \%$ higher than the mean of the HPLC values. Moreover, a paired $t$-test of the values measured by the 2 methods for each of 6 patients from whom at least 3 samples were available, revealed no significant difference for any patient $(p>0.05)$.

Thus, these results show that if plasma theophylline concentrations are measured using the improved cartridges and apparatus of the Biotrack system, reliable values are obtained which correlate well with those obtained by HPLC, irrespective of the individual blood characteristics of the patients. 


\section{Conclusion}

We found that some combinations of Biotrack 516 units and cartridges afforded high theophylline concentrations for some patients on account of unknown blood characteristics. The reliability of the system increased after modifications of the cartridge and measuring apparatus were introduced. We regard the utility of the system as particularly high in cases where theophylline measurement is urgent.

\section{Acknowledgements}

The authors hereby express their gratitude to Eisai Co. Ltd., Sanko Pure Chemicals Co. Ltd., and CibaCorning Diagnostics Co. Ltd., for providing the Biotrack cartridges and measuring apparatus employed in the present study.

\section{References}

1) L. Hendeles, M. Weinberger, G. Johnson., Clin. Pharmacokin., 3, 294-312 (1978).

2 ) I. Gibbons, M. Gorin, Z. Yassinzadeh, P. Peterson, D. Besemer, K. Dillon, T. Burd, R. Hillman, G. Smoluk, M. Cobb, Clin. Chem., 35, 1869-1873 (1989).

3 ) H. Kodera, M. Misawa, S. Yanaura, T. Iwata, N. Kobayashi, K. Ishimura, H. Hayakawa, Allergy, 34, 33-46 (1985).

4 ) Y. Hamasaki, T. Ichimaru, S. Miyazaki, Jap. J. Clin. Chem., 15, 44-50 (1986).

5 ) S. Ishizawa, C. G. Kang, Y. Takagi, K. Gomi, T. Matsumoto, Y. Sakamoto, M. Arita, Laboratory Test Apparatus and Reagents, 16, 707-712 (1993).

6 ) T. Shimizu, H. Mochizuki, K. Tokuyama, A. Morikawa, T. Kuroume, T. Kimura, K. Tateno, Medicine and Pharmacology, 29, 741-748 (1993).

7 ) T. Nakamura, T. Horiuchi, I. Jhono, S. Kitazawa, Therap. Res., 3, 147-153 (1985).

$8)$ H. Hishida, A. Takahashi, Y. Abe, T. Suzuki, E. Saji, K. Mizuno, Jpn. J. Hosp. Pharm., 11, 312-317 (1985).

9) J. Inatomi, J. Kizu, S. Watanabe, Y. Inomata, K. Watanabe, K. Sasaki, K. Watanabe, M. Noda, T. Igarashi, T. Iwata, H. Hayakawa, Jpn. J. Pediatrics, 48, 143-147 (1995).

10) Y. Horai, T. Ishizaki, T. Sasaki, Eur. J. Clin. Pharmacol ., 23, 111-121 (1982).

11) B. Cuzack, J. G. Kelly, J. Lavan, Br. J. Clin. Pharmacol ., 10, 109-114 (1980).

12) J. Jenne, H. Nagasawa, R. Mchugh, Life Sci., 17, 195-198 (1975).

13） S. N. Hunt, W. J. Jusko, A. M. Yurchak, Clin. Pharmacol. Ther., 19, 546-551 (1976). 